\title{
Cardiac PET imaging: Lost in quantification. It's time to find the way
}

\author{
Emilia Zampella, MD, PhD, ${ }^{\text {a }}$ Roberta Assante, $M D, P h D,{ }^{a}$ Wanda Acampa, MD, \\ $\mathrm{PhD},{ }^{\mathrm{a}, \mathrm{b}}$ and Alberto Cuocolo, $\mathrm{MD}^{\mathrm{a}}$ \\ a Department of Advanced Biomedical Sciences, University Federico II, Naples, Italy \\ b Institute of Biostructure and Bioimaging, National Council of Research, Naples, Italy
}

Received Aug 5, 2020; accepted Aug 5, 2020

doi: $10.1007 / \mathrm{s} 12350-020-02332-9$

\section{See related article, pp. 1236-1248}

Cardiac imaging with positron-emission tomography (PET) affords non-invasive measurements of myocardial blood flow (MBF) and myocardial perfusion reserve (MPR), improving traditional nuclear medicine in diagnosis and risk stratification of patients with coronary artery disease (CAD). ${ }^{1-3}$ These measurements can be obtained in few minutes with appropriate software packages by applying tracer kinetic modeling to dynamic PET images. Any numerical value that we receive from dynamic cardiac PET results from this transformation. It should be considered that several technical aspects can affect MBF and MPR measurements, including physical and biochemical properties of different tracers and specific features of PET instrumentations. ${ }^{4-6}$ For clinic applications, ${ }^{82}$ Rubidium $\left({ }^{82} \mathrm{Rb}\right)$ is the most widely used tracer, considering that it is generator-produced and it does not require a cyclotron in site. Several software tools for absolute quantification of dynamic PET with ${ }^{82} \mathrm{Rb}$ have been developed and a comparison between those commercially available software programs have been already performed. ${ }^{7-9}$ In particular, Nesterov et $\mathrm{al}^{7}$ compared 8 tools on the same set of data and they found that different software provided similar results when the same kinetic model was applied. However, it should be also taken into account that quantitative analysis of cardiac PET imaging is a challenging process and kinetic model is the latest in a

Reprint requests: Roberta Assante, MD, PhD, Department of Advanced Biomedical Sciences, University Federico II, Via Pansini 5, 80131 Naples, Italy; roberta.assante@libero.it

J Nucl Cardiol 2021;28:1249-51.

$1071-3581 / \$ 34.00$

Copyright (C) 2020 American Society of Nuclear Cardiology. series of steps that can affect the results, including reconstruction, segmentation, quality control, and outputting the values. In particular, segmentation is a crucial step that precedes kinetic modeling and allows to localize the left ventricular (LV) myocardium and the blood in its cavity in order to obtain time activity curves (TAC). For this purpose, regions of interest (ROI) of the LV cavity and myocardium can be used. Definition and placement of ROI, as well as reorientation process from transverse images into a standard cardiac orientation and differences in tissue sampling between rest and stress series, may need more than one of the manual interventions and affect the results when different software packages are considered. ${ }^{7-11}$ Semiautomatic and automatic segmentation methods, based on various statistical scenarios, have been proposed to improve the reproducibility of PET quantification. ${ }^{12-14}$ Factor analysis is widely used for extracting tissue TAC in dynamic PET images. ${ }^{13}$ This approach is based on the assumption that dynamic PET noise and the model approximation errors follow Gaussian distributions. Differently, non-negative matrix factorization (NMF) uses Poisson statistics as noise model. But these statistical approaches were developed primarily with an assumption of homogeneous radiotracer uptake in the same organ and they do not fully take into account the partial volume effect commonly exists in dynamic cardiac PET. More recently, a triple-factor non-negative matrix factorization (TNMF) method for semiautomatic LV cavity and myocardial segmentation has been proposed and it has been found to be highly feasible for MBF and MPR quantification. $^{14}$

In the current issue of Journal of Nuclear Cardiology, Liu et $\mathrm{al}^{15}$ proposed a new software tool called "Yale-MQ,' based on an optimized TNMF segmentation workflow and on one-tissue compartment model. The authors evaluated quantitative precision and intra-/ inter-observer variabilities of Yale-MQ in MBF and 
MFR quantification in a cohort of normal healthy volunteers $(n=18)$ and a group of CAD patients $(n=62)$ who underwent cardiac imaging by ${ }^{82} \mathrm{Rb}$. The results obtained by using Yale-MQ were compared with those obtained by using a commercially available software (Corridor4DM, Ann Arbor, MI) as reference standard. The success rate of processing the dynamic PET images by using automatic Yale-MQ was substantially comparable to Corridor4DM (81\% vs. $75 \%$ ). According to previous studies, ${ }^{1,16}$ patients with CAD showed similar rest MBF values, but lower stress MBF and MPR values as compared to normal subjects, at both quantification methods. No differences in global and regional MBFs and MPR, as well as in lower normal limits, were observed between the two software. Moreover, the agreement between Yale-MQ and Corridor4DM was tested by using different statistical methods and it resulted to be excellent, with a high correlation coefficient $(R \geq 0.867)$ and intra-class correlation coefficient (ICC $\geq 0.862$ ). Both intra- and inter-observer variability for Yale-MQ calculation resulted to be excellent.

In the study of Liu et al, ${ }^{15}$ several points deserve to be highlighted. The one-tissue compartment model described by Lortie et $\mathrm{al}^{17}$ is the most commonly used with ${ }^{82} \mathrm{Rb}$ PET software. The Yale-MQ is based on the use of an optimized TNMF segmentation workflow to obtain TAC, on which one-tissue compartment model is applied. Considering that different software tools provide similar data when the same kinetic model is applied, Yale-MQ provides results that can be used interchangeably with other programs in the presence of the same dynamic protocol. The TNMF segmentation method is based on the assumption that dynamic PET imaging can be represented as the product of three matrices of organ template, organ TAC, and system point spread function (PSF). The PSF matrix has an important role in limiting partial volume effect, ensuring that the voxels suffering from serious partial volume effect can be clustered correctly. It should be also considered that the TNMF method incorporating the PSF into the factorization model provides beneficial results in the presence of high-noise PET imaging. Currently, there is great interest in finding new strategies for reduce dose administration, enabling radionuclide imaging to be more cost-effective and improving patient and medical staff protection. ${ }^{18}$ Yet, reducing the injected dose may lead to lower imaging quality, with a significant increase of noise that could affect MBF quantification. In the light of the above, we must promote solutions allowing good imaging quality despite dose reduction. Moreover, in order to fit the shape of the LV myocardium, Yale-MQ applies an ellipsoid model, which is coupled with the initial myocardial ROI obtained from the TNMF segmentation. This allows to compensate for the extreme case of severe myocardial perfusion defects. In their population, $31(50 \%)$ patients of the CAD group were referred to coronary catheterization; the good percentage of patients with known CAD allowed to test the Yale-MQ software also in patients with large perfusion defects. ${ }^{15}$ Hence, this new quantification method seems to be highly reproducible and feasible for clinical application.

Despite the promising features mentioned above, it is time to make some considerations. Nowadays, we are getting lost in the numbers. In addition to the high number of available quantification tools, it should be considered the emerging role of CZT cameras in dynamic cardiac imaging. ${ }^{19-21}$ In the latest years, research focused on these new CZT-SPECT and the opportunity of performing absolute quantification of MBF and MPR even in those nuclear medicine laboratories without PET equipment. ${ }^{19-21}$ The risk is to be submerged by a large amount of different values produced by different systems, different tracers, different software, without being able to give each of these a single meaning. We would wonder if cardiac imaging really needs further quantitative tools or to optimize available resources, whereas the goal must be to obtain the best option that takes into account the different types of scanner, tracers, and protocols. It is certainly necessary to test all the tools and understand their strengths and weaknesses. However, it is only supporting the creation and improvement of reorientation, segmentation, quality control, and kinetic algorithms that we will be able to make quantitative cardiac imaging more accurate and reproducible. In the future, the right way will be to make the data uniform and interchangeable among nuclear cardiology laboratories.

\section{Disclosure}

Emilia Zampella, Roberta Assante, Wanda Acampa, and Alberto Cuocolo declare that they have no conflict of interest.

\section{References}

1. Naya M, Murthy VL, Taqueti VR, Foster CR, Klein J, Garber M, et al. Preserved coronary flow reserve effectively excludes highrisk coronary artery disease on angiography. J Nucl Med 2014;55:248-55.

2. Gaudieri V, Acampa W, Rozza F, Nappi C, Zampella E, Assante $\mathrm{R}$, et al. Coronary vascular function in patients with resistant hypertension and normal myocardial perfusion: A propensity score analysis. Eur Heart J Cardiovasc Imaging 2019;20:949-58.

3. Zampella E, Acampa W, Assante R, Gaudieri V, Nappi C, Mannarino $\mathrm{T}$, et al. Combined evaluation of regional coronary artery calcium and myocardial perfusion by ${ }^{82} \mathrm{Rb} \mathrm{PET} / \mathrm{CT}$ in predicting 
lesion-related outcome. Eur J Nucl Med Mol Imaging 2020;47:1698-704.

4. Gould KL, Johnson NP, Bateman TM, Beanlands RS, Bengel FM, Bober R, et al. Anatomic versus physiologic assessment of coronary artery disease. Role of coronary flow reserve, fractional flow reserve, and positron emission tomography imaging in revascularization decision-making. J Am Coll Cardiol 2013;62:1639-53.

5. deKemp RA, Renaud JM, Klein R, Beanlands RS. Radionuclide tracers for myocardial perfusion imaging and blood flow quantification. Cardiol Clin 2016;34:37-46.

6. van Dijk JD, Jager PL, van Osch JAC, Khodaverdi M, van Dalen JA. Comparison of maximal Rubidium-82 activities for myocardial blood flow quantification between digital and conventional PET systems. J Nucl Cardiol 2019;26:1286-91.

7. Nesterov SV, Deshayes E, Sciagrà R, Settimo L, Declerck JM, Pan $\mathrm{XB}$, et al. Quantification of myocardial blood flow in absolute terms using (82)Rb PET imaging: The RUBY-10 Study. JACC Cardiovasc Imaging 2014;7:1119-27.

8. deKemp RA, Declerck J, Klein R, Pan X, Nakazato R, Tonge C, et al. Multi software reproducibility study of stress and rest myocardial blood flow assessed with 3D dynamic PET/CT and a 1-tissue compartment model of ${ }^{82} \mathrm{Rb}$ kinetics. J Nucl Med 2013;54:571-7.

9. Tahari AK, Lee A, Rajaram M, Fukushima K, Lodge MA, Lee $\mathrm{BC}$, et al. Absolute myocardial flow quantification with (82)Rb PET/CT: Comparison of different software packages and methods. Eur J Nucl Med Mol Imaging 2014;41:126-35.

10. Ross SG, Welch A, Gullberg GT, Huesman RH. An investigation into the effect of input function shape and image acquisition interval on estimates of washin for dynamic cardiac SPECT. Phys Med Biol 1997;42:2193-213.

11. Vasquez AF, Johnson NP, Gould KL. Variation in quantitative myocardial perfusion due to arterial input selection. JACC Cardiovasc Imaging 2013;6:559-68.

12. Margadán-Méndez M, Juslin A, Nesterov SV, Kalliokoski K, Knuuti J, Ruotsalainen U. ICA based automatic segmentation of dynamic H2O15 cardiac PET images. IEEE Trans Inf Technol Biomed 2010;14:795-802

13. El Fakhri G, Sitek A, Guérin B, Kijewski MF, Di Carli MF, Moore SC. Quantitative dynamic cardiac ${ }^{82} \mathrm{Rb}$ PET using generalized factor and compartment analyses. J Nucl Med 2005;46:1264-71.
14. Liu H, Wu J, Sun JY, Wu TH, Ramesh FC, Thorn S, et al. A robust segmentation method with triple-factor non-negative matrix factorization for myocardial blood flow quantification from dynamic 82Rb positron emission tomography. Med Phys 2019;46:5002-13.

15. Liu H, Thorn S, Wu J, Fazzone-Chettiar R, V Sandoval, Miller EJ, et al. Quantification of myocardial blood flow (MBF) and reserve (MFR) incorporated with a novel segmentation approach: Assessments of quantitative precision and the lower limit of normal MBF and MFR in patients J Nucl Cardiol. (in press).

16. Zampella E, Acampa W, Assante R, Nappi C, Gaudieri V, Mainolfi $\mathrm{CG}$, et al. Combined evaluation of regional coronary artery calcium and myocardial perfusion by ${ }^{82} \mathrm{Rb} \mathrm{PET} / \mathrm{CT}$ in the identification of obstructive coronary artery disease. Eur J Nucl Med Mol Imaging 2018;45:521-9.

17. Lortie M, Beanlands RSB, Yoshinaga K, Klein R, Dasilva JN, Dekemp RA. Quantification of myocardial blood flow with ${ }^{82} \mathrm{Rb}$ dynamic PET imaging. Eur $\mathrm{J}$ Nucl Med Mol Imaging 2007;34:1765-74.

18. Case JA, deKemp RA, Slomka PJ, Smith MF, Heller GV, Cerqueira MD. Status of cardiovascular PET radiation exposure and strategies for reduction: An Information Statement from the Cardiovascular PET Task Force. J Nucl Cardiol 2017;24:1427-39.

19. Acampa W, Assante R, Mannarino T, Zampella E, D'Antonio A, Buongiorno $\mathrm{P}$, et al. Low-dose dynamic myocardial perfusion imaging by CZT-SPECT in the identification of obstructive coronary artery disease. Eur $\mathrm{J}$ Nucl Med Mol Imaging 2020;47:1705-12.

20. de Souza ACDAH, Gonçalves BKD, Tedeschi AL, Lima RS. Quantification of myocardial flow reserve using a gamma camera with solid-state cadmium-zinc-telluride detectors: Relation to angiographic coronary artery disease. J Nucl Cardiol 2019. http s://doi.org/10.1007/s12350-019-01775-z.

21. Acampa W, Zampella E, Assante R, Genova A, De Simini G, Mannarino T, et al. Quantification of myocardial perfusion reserve by CZT-SPECT: A head to head comparison with 82Rubidium PET imaging. J Nucl Cardiol 2020. https://doi.org/10.1007/s1235 0-020-02129-w.

Publisher's Note Springer Nature remains neutral with regard to jurisdictional claims in published maps and institutional affiliations. 